\title{
Demographics and spatial ecology in a population of cryptic wood white butterfly Leptidea juvernica in Northern Ireland
}

\author{
James $\mathrm{O}^{\prime} \mathrm{Neill}^{1,2}$ (D) Ian Montgomery ${ }^{1}$ \\ Received: 29 January 2018 / Accepted: 17 July 2018 / Published online: 28 July 2018 \\ (c) The Author(s) 2018
}

\begin{abstract}
The cryptic wood white Leptidea juvernica is one of a newly-discovered species complex comprising three morphologically similar species in Europe. In the British Isles, L. juvernica is absent from Great Britain, but is widespread in Ireland, where it has experienced recent declines; it is classed as a priority species in Northern Ireland. Using a mark-recapture approach, this study aims to elucidate the population and spatial ecology of L. juvernica based on a population resident on a small, suburban site and to propose conservation measures. The results demonstrated that populations of L. juvernica, even on small sites, can reach high numbers during the peak flight season. Unusually for European Pieridae, there was only weak evidence of protandry in this population, possibly reflecting weather conditions prior to the flight season. The spatial distribution and abundance of $L$. juvernica was associated with the distribution of its larval host-plants, as well as maintaining close proximity to south-facing habitat edges for shelter. Males had a closer association to sheltered habitat edges, whilst females were found more commonly on open ground with a shorter sward which was the preferred egg-laying habitat. Long vegetation in sheltered areas was important for roosting during periods of non-activity. These results inform conservation measures which will benefit $L$. juvernica; appropriate measures focus on habitat management providing a mosaic of open, semi-natural grassland interspersed with tall vegetation, scrub, and trees.
\end{abstract}

Keywords Cryptic wood white $\cdot$ Leptidea juvernica $\cdot$ Pieridae $\cdot$ Population ecology $\cdot$ Spatial ecology $\cdot$ Host plant distribution $\cdot$ Butterfly conservation

\section{Introduction}

Differences in the ecologies of cryptic species may be highly important in implementing specific measures for their conservation. This is particularly relevant in European butterflies, many of which have experienced dramatic population declines (Bickford et al. 2007; Thomas 1995). Butterflies are useful indicators for sensitive habitats, and provide important ecological functions, such as pollination (Jennersten 1984) and as a food source for other arthropods and birds.

James O’Neill

oneill_james@hotmail.co.uk

Ian Montgomery

i.montgomery@qub.ac.uk

1 Institute of Global Food Security, School of Biological Sciences, Queen's University Belfast, Belfast,

Northern Ireland BT9 7BL, UK

2 Craigavon, UK
Conserving and managing habitats for butterflies, therefore, benefits a great range of other plant and invertebrate species.

Recent work by Dincă et al. (2011) revealed using molecular methods that the European Leptidea sinapis (Pieridae) complex comprises three separate species: L. sinapis (L.), which is widespread across Europe including the British Isles; L. reali (Reissinger 1989), which is localised in southern France, Italy, and Spain; and the newly-described L. juvernica (Williams 1946), which forms a sister group to the former two species, and is also widespread across Europe. Nelson et al. (2001) confirmed the presence of both $L$. sinapis and $L$. juvernica (then $L$. reali) in Ireland but only the existence of $L$. sinapis in Great Britain. The two species are not regarded as sympatric in Ireland, with $L$. sinapis known only from limestone areas in counties Clare and Galway, while $L$. juvernica is found nearly everywhere else on the island (Thomas 2010; Nash et al. 2012).

Known niche specialisations of $L$. juvernica and $L$. sinapis, where they occur sympatrically in Europe, reveal a complex situation where each species varies in its habitat 
preferences and specialisation, depending on its geographic location. In the Czech Republic, L. sinapis specialises in xerothermic habitats, whereas L. juvernica is a generalist, found in most habitat types (Beneš et al. 2003). Similarly, in Poland, $L$. juvernica is a generalist, showing no preference for specific humidity levels, whereas $L$. sinapis has a more constrained distribution and is associated with woodland and xerothermic habitats (Sachanowicz et al. 2011). In contrast, in Sweden, $L$. juvernica is restricted to rare, fragmented open meadow habitats, whilst $L$. sinapis is considered a generalist, found over a broad range of habitats, including forest (Friberg et al. 2008). In the Balkans, L. sinapis is considered a widespread habitat generalist, and the habitat selectivity of $L$. juvernica ranges from habitat generalist in the west to specialist in the east, where it is restricted to upland, humid habitats. In the British Isles, there is a clear difference in the habitat requirements between L. sinapis and L. juvernica, but the ecology of L. juvernica is not well understood. In Britain, most $L$. sinapis populations are restricted to mature woodland habitat, including plantation woodland (Clarke et al. 2011), inhabiting open woodland rides and margins (Warren et al. 1986; Thomas 2010). In Ireland, L. sinapis is associated mostly with wooded and sheltered scrubby areas in limestone pavement areas (Nash et al. 2012). In contrast, L. juvernica in Ireland appear to have no direct dependence on woodland, and is associated with relatively open sites, such as flower-rich grassland, bog edges, abandoned quarries and sand dunes (Thompson and Nelson 2006). Despite these differences in habitat preference, both species are oligophagous, using the same larval host-plants in the family Fabaceae, including Lathyrus pratensis, Lotus pedunculatus and Lotus corniculatus (Warnock 2008; Friberg and Wiklund 2009; Clarke et al. 2011). Although L. sinapis is relatively well studied in Britain (Warren 1984; Warren et al. 1986; Jeffcoate 2006; Clarke et al. 2011; Jeffcoate and Joy 2011), the habitat usage and requirements of Leptidea spp. have not been researched adequately in Ireland, especially given the ecological plasticity apparent throughout their European range, and the cool temperate conditions prevailing on the westernmost edge of their range.

Despite a historical expansion northward across Ireland (Heal 1965), recent declines of L. juvernica (Staats and Reagan 2014) merit its current status as a Northern Ireland Priority Species (Allen and Mellon 2006). Practical conservation work to curb the population decline, by improving existing breeding habitat, creating new breeding habitat and linking existing colonies and sub-colonies with corridors of suitable habitat to facilitate movements between populations requires a more intimate understanding of the habitat requirements and usage of L. juvernica.

The present paper elucidates the ecology of $L$. juvernica in Ireland, including their population dynamics within a flight season, movements within and outside the primary breeding area of a population, use of different vegetation types within their flight area, and larval host-plant preferences. Particular attention is paid to the comparison of male and female behaviour, with regard to flight time, spatial ecology, and use of resources. These data will inform proposals for the conservation of L. juvernica in Ireland, and will provide a wider understanding of how the ecology of Leptidea spp. varies across Europe.

\section{Methods}

\section{Study site}

The study site was located at Edenderry, Portadown, County Armagh, Northern Ireland (Irish grid: IJ016540). It is surrounded to the north, west, and east, by roads, industrial areas and suburbs, including gardens. The southern edge of the site borders the floodplain of the River Bann, which is mainly improved pasture and rush-dominated marshland. The study site (hereafter known as Edenderry) is privately owned, and covers an area of 4.038 ha, comprising a variety of habitats including young willow, alder and oak woods; gorse and willow scrub; brownfield waste ground; and unimproved grassland and marsh. Most of the grassland and scrub was found on recently disturbed areas and thus have developed since 2009, when pipe-laying works demolished many of the young trees which were previously present, changed the topography of the site, and overturned the ground to expose nutrient-poor subsoil. Leptidea sp. is a recent colonist of the site, and was first recorded in June 2013, when a single female was observed ovipositing on the east side of the site. The population was observed to increase in abundance from year to year between 2013 and 2016, with maximum daily counts of 1 in 2013, 15 in 2014, 27 in 2015, and 53 in 2016. The species was reliably identified as L. juvernica, based on geographical location, morphological features of the chrysalis (Thomas 2010), the courtship display, which differs between the two species (Thomas 2010), and determination of nearby populations as $L$. juvernica based on examination of male genitalia (Warnock 2008). The main larval host-plant, meadow vetchling $L$. pratensis is abundant in the study area. Greater bird's-foot trefoil Lotus peduncularis, another known larval host-plant, is also present, but at low density. The area of open, unimproved grassland and waste ground was the preferred habitat for adult $L$. juvernica and measured 1.52 ha (38\% of the total site area). Forest, marsh, and thick scrub were generally avoided during fieldwork due to their inaccessibility and unsuitability as habitats for adult L. juvernica.

This population of $L$. juvernica appears to be largely isolated. Larval host-plant species are rare within at least a $1.2 \mathrm{~km}$ radius around the study site, and the tiny patches 
of host-plants which occur are insufficient to support sustainable populations. The five nearest known extant stable breeding colonies are between 3.1 and $8.1 \mathrm{~km}$ away. Movements by individuals between those sites and the study area are likely to be limited by the distance, and obstacles such as extensive urban areas, roads, woodland, open water and open pasture.

During the period when adult $L$. juvernica were active, some areas of rank grassland were noticeably taller than the rest of the grassland areas, usually with a sward height of greater than $40 \mathrm{~cm}$. These areas were largely dominated by cock's foot grass Dactylis glomerata, Yorkshire fog Holcus lanatus, stinging nettle Urtica dioica and creeping thistle Cirsium arvense, and indicated nutrient-enriched soil. As these formed a distinct habitat type within the study area, these areas of rank grassland were mapped out using a GIS. The distribution of the main larval host-plant, meadow vetchling $L$. pratensis, was also mapped.

\section{Mark-release-recapture study}

Edenderry, as a relatively small and accessible site, was suitable for an extensive mark-release-recapture study on $L$. juvernica. It facilitated adequate daily survey intensity of the area during the flight season, which maximised the chances of obtaining a high percentage of recaptures, which is critical in maximising precision of estimates in mark-recapture population analysis models. The isolation of this population from other $L$. juvernica populations substantiates an assumption that there a minimal level of immigration of individuals from outside sources.

Mark-release-recapture on adult $L$. juvernica was undertaken in 2016. The earliest recorded emergence of L. juvernica in Northern Ireland is the 9th April (Thompson and Nelson 2006), but the peak flight season generally takes place between early May and late June. The site was inspected daily from 1st May, in order to detect the first emergence of adult butterflies. Over a period of 38 days, from the first observed L. juvernica emergence on the 11th May until 17th June, there were 27 survey events. Surveys were conducted once per day, except on days with prolonged rain, low temperatures or overcast conditions, when no survey attempts were made. Survey start times were weather dependent and ranged between 12.00 and $4.32 \mathrm{pm}$. These survey times avoided the 'morning lull', when L. juvernica tended to be less active at the study site, most likely due to long shadows from surrounding trees causing shade and lower temperatures. Daily weather data, including maximum and minimum temperature, rainfall, total sunshine, and wind speed and direction, for each day during the survey period was obtained from the weather station at the Armagh Observatory, which is located $16.2 \mathrm{~km}$ southwest from the study site and likely to have experienced similar weather conditions.

During each survey event, a standard survey route was walked once per day, beginning on the east side of the study area, and ensuring that as much of the accessible area within the site as possible was covered. A hand-net was used to catch any $L$. juvernica within approximately $10 \mathrm{~m}$ from the survey route, depending on accessibility and likelihood of capturing the butterflies unharmed. New butterflies were marked with a series of dots, using a fine-tipped permanent marker, on their hindwing undersides, using the 1-2-4-7 system, modified from Watt et al. (1977). Every butterfly was, thereafter, individually recognisable upon recapture. The unique number of each individual was recorded on successive recaptures. The physical condition of each captured butterfly was rated, following Konvička and Kuras (1999), on a scale of 1-4, as follows: (1) freshly emerged, no visible damage; (2) minor damage and/or wear to the wings; (3) moderate damage, tearing and wear to the wings; and, (4) extensive damage and wear to the body/wings. The location of each capture was plotted on a hard copy of a line map of the area; this was faster and often more efficient than using a hand-held GPS for generating exact locations, particularly on very busy days, and in instances where a butterfly had to be processed away from where it was caught. The time of capture, sex, activity immediately before capture (flight, resting, ovipositing, etc.) and additional notes were also recorded for each capture. After processing, each butterfly was released gently onto vegetation as close as possible to where it had been captured. At the end of each survey, frequent, wide-ranging searches on the river Bann floodplain to the south of Edenderry to a limit of $1 \mathrm{~km}$ from the study area were conducted to record any L. juvernica which had wandered off the study site. Opportunistic captures at any other time and off-site locations were also recorded.

\section{Data analysis}

Population demographic analysis was performed using Program MARK, v.8.0. Initially, a Cormack-Jolly-Seber model approach was used to determine survival rate/emigration $(\phi)$ and probability of capture $(p)$, incorporating the effects of sex and time. It was assumed that the sex would influence capture probability, as male Leptidea are more likely to be encountered due to their higher levels of activity (Warren et al. 1986); thus, data representing each sex was analysed separately. The best-fitting model from this approach was used as a starting point in the POPAN module in Program MARK. POPAN is a robust form of the Jolly-Seber approach to mark-recapture analysis, and directly estimates the parameters: $\phi, p$, probability of entry into population/ combined births and immigration (pent), and total population size $\left(N_{t o t}\right)$. Derived parameters are: daily population 
size $\left(N_{i}\right)$ and daily number of emergences $\left(b_{i}\right)$. Four models for each analysis were run, each varying as to whether time ( $t)$ affected $\phi$ and $p:\{\phi(t) p(t)\} ;\{\phi(\mathrm{t}) \mathrm{p}(\cdot)\} ;\{\phi(\cdot) p(t)\}$; $\{\phi(\cdot) p(\cdot)\}$. The model which best fitted the variance in the data was selected as the one with the lowest Akaike information criterion $\left(\mathrm{AIC}_{\mathrm{c}}\right)$ values in relation to all competing models. Same-day recaptures were not included in this analysis.

The precise location for each capture was plotted onto a digital shapefile using GIS. Kernel density heat maps were produced to show the distributions of females, males, and all captures to correlate comparable distributions. The GIS was used to measure distances between consecutive recaptures for each individual butterfly, and to obtain the distance between each capture and: (a) the nearest patch of $L$. pratensis, (b) the nearest habitat edge, which was defined as the distinct border between open habitats preferred by $L$. juvernica, and tall woody vegetation which mostly occurred along the edge of the study area.

\section{Results}

\section{Population demographics}

There were 889 captures (64.1\% male; $35.9 \%$ female) of $L$. juvernica recorded over a 38-day period (Table 1), with 228 individuals (53.9\% male; $46.1 \%$ female) marked on or near the study site. The recapture rate was high (including sameday recaptures), with $66.3 \%$ ( $60.9 \%$ male; $39.1 \%$ female) of all marked individuals recaptured at least once; in total there were 661 recaptures (67.6\% male; $32.4 \%$ female). The mean observed residence time (time duration between first and last captures for each individual) was significantly longer (Mann-Whitney U test; $\mathrm{p}<0.05$ ) in males (5.4 days; $\pm 0.4 \mathrm{SE}$ ) than females ( 4.2 days; $\pm 0.4 \mathrm{SE}$ ), while the maximum observed residence time was 19 days for males and 18 days for females.

According to the model with the best fit (i.e. with the lowest $\mathrm{AIC}_{\mathrm{c}}$ value), survival rate $(\phi)$ varied between the sexes, but not over time, remaining constant at $0.84( \pm 0.01 \mathrm{SE})$ for males, and $0.81( \pm 0.02 \mathrm{SE})$ for females. Encounter rates $(p)$ varied between the sexes but remained constant over time at $0.65( \pm 0.03)$ for males, and $0.60( \pm 0.03)$ for females, while recruitment rates (pent) depended on time, and also varied between the sexes.
The estimated values for $N_{t o t}$ were $135( \pm 4.1 \mathrm{SE})$ for males and $121( \pm 5.2 \mathrm{SE})$ for females, giving a total population estimate of 256 during the survey period. The number of individuals marked (228) during the study suggests that $89.1 \%$ of the population was captured. The estimated populations of males and females $\left(N_{i}\right)$ over the study period (Fig. 1) were positively correlated (Spearman's rank; $r=0.78 ; p<0.01$ ), indicating that numbers of each sex fluctuated similarly across the season, although males outnumbered females most of the time. Numbers of both sexes peaked on the 30th May, with an estimated $46( \pm 5.5$ $\mathrm{SE})$ males and $32( \pm 5.3 \mathrm{SE})$ females present. Before this peak abundance, numbers fluctuated considerably, with a sharp drop in numbers of both males and females between the 24th and 27th May, coinciding with a sharp drop in daily maximum temperature to a low of $13^{\circ} \mathrm{C}$. After 30th May, numbers of males decreased gradually until the end of the survey period, whereas females continued a relatively stable population peak at numbers ranging between 28 and 34, until 8th June, after which they decreased in number, more sharply than the males, until the end of the survey period. On the final survey event, there were an estimated $5( \pm 1.5 \mathrm{SE})$ males and $8( \pm 2.6 \mathrm{SE})$ females. The survey period ended before the flight season had completely finished, although it covered most of the main flight season.

All marked individuals were rated as a 1 for body condition when initially captured and marked. However, 29 individual L. juvernica (21 males, 8 females; $\mathrm{n}=228$, $\left.\chi^{2}=4.56, \mathrm{df}=1, \mathrm{p}<0.05\right)$ were observed to have heavily damaged wings (rated 4 for body condition) at subsequent recapture events. This included one or both forewings broken, snapped or missing from the base, one or both missing hindwings, and large tears through wings. Even with these injuries, most were still able to fly to some extent, though less efficiently. The average number of days' survival, after initial capture, when these injuries were recorded was 6.5 $(\min =1, \max =15)$. Active predation of adult $L$. juvernica was not observed, despite multiple observed instances of common predators of butterflies, such as dragonflies and spotted flycatchers Muscicapa striata, which had opportunities to catch the slow-flying $L$. juvernica. On two occasions, $L$. juvernica were found deceased in spider webs in low vegetation, apparently untouched by the resident spiders which were sheltering nearby.
Table 1 Summary of the number of initial captures, recaptures and total captures for males and females

\begin{tabular}{llcll}
\hline & $\begin{array}{l}\text { Initially marked } \\
\text { individuals }\end{array}$ & $\begin{array}{l}\text { Recaptured individuals }(\% \text { of } \\
\text { initially marked) }\end{array}$ & Total recaptures & Total captures \\
\hline Male & 123 & $92(74.7)$ & 447 & 570 \\
Female & 105 & $69(65.7)$ & 214 & 319 \\
Total & 228 & $151(66.3)$ & 661 & 889 \\
\hline
\end{tabular}


Fig. 1 The daily population estimates of L. juvernica adults across the survey period, as estimated by the best fit model in POPAN. Standard error bars are shown. The maximum daily temperature is shown as a dashed grey line

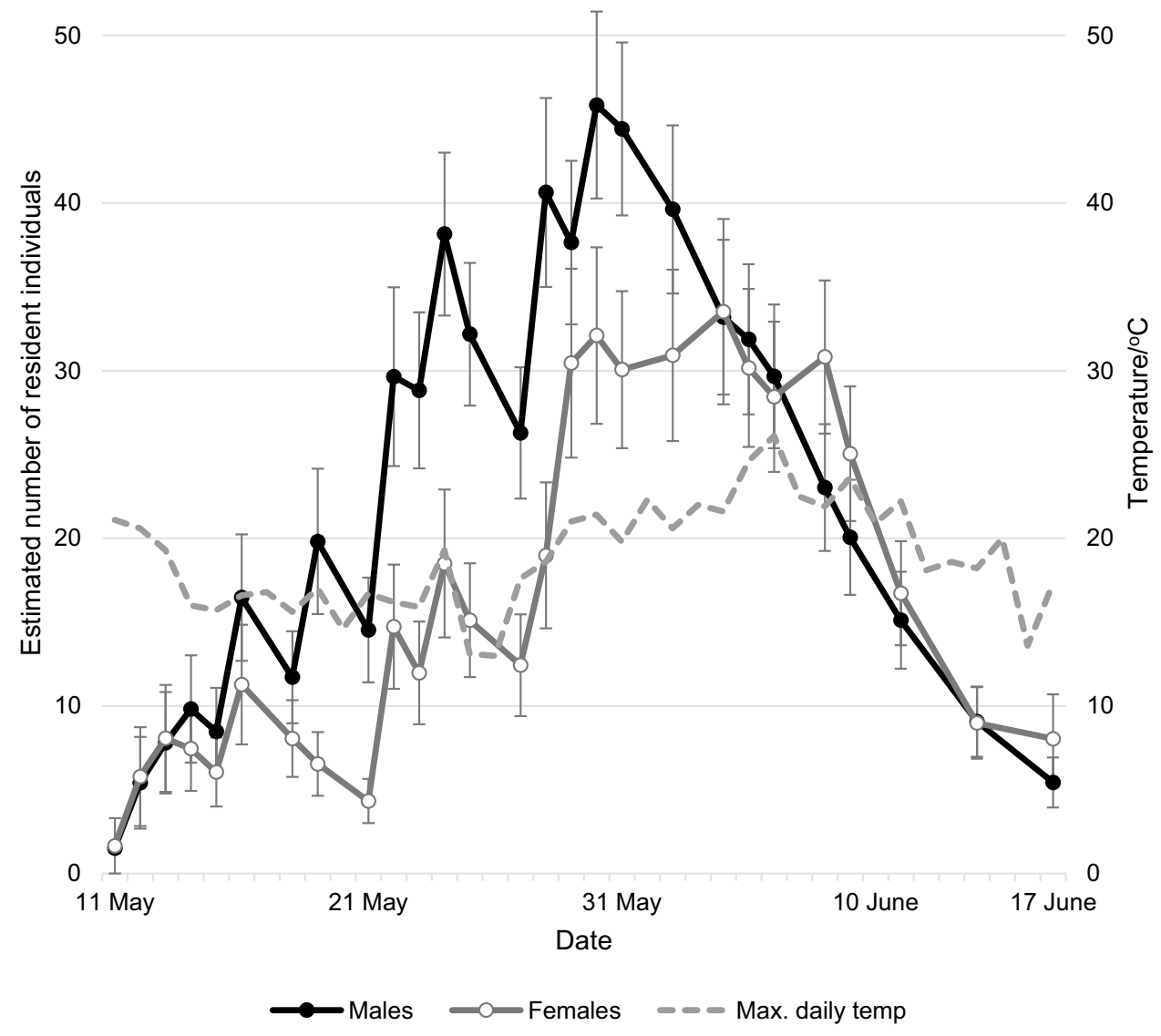

\section{Spatial distribution}

The spatial distribution of L. juvernica, based on the locations of all captures, was non-random and clustered across the study area (Nearest Neighbour Ratio $=0.56 ; \mathrm{p}<0.001$ ), and was mainly concentrated on the eastern side of the study area (Fig. 2a). Similarly, the distribution of the main larval host-plant, meadow vetchling L. pratensis was also biased towards the east side of the study area, with small patches across the centre and south-west, and none present in the north-west area (Fig. 2b). The average distance from each capture to the nearest patch of L. pratensis was $1.1 \mathrm{~m}$, significantly smaller (Mann-Whitney U test; $p<0.001)$ than the average distance, $14.0 \mathrm{~m}$, derived from a distribution of random points across the study area (Fig. 3). Forty-four percent of captures of $L$. juvernica were recorded in a location where L. pratensis was also present, whereas only $19 \%$ of random points overlapped with the distribution of $L$. pratensis, suggesting that the overall distribution of $L$. juvernica was closely associated with the distribution of its larval host-plant.

The average distance from each capture to the nearest habitat edge was $9.8 \mathrm{~m}$, which was significantly smaller (Mann-Whitney U test; $p<0.001$ ) than the average distance of $14.3 \mathrm{~m}$ derived from the random-points distribution. This suggests that $L$. juvernica was associated with the habitat edges at Edenderry, as well as with $L$. pratensis, making the north-east habitat edge of the study area the most favoured by L. juvernica (Fig. 2a).

The distributions of females and males (Fig. 2c, d) were correlated $\left(r_{s}=0.74, p<0.001\right)$, suggesting that the sexes have partially overlapping distributions across the study area. This was further explored by examining the proximities of males and females to L. pratensis, and to habitat edges. The average distance from each male capture to the nearest $L$. pratensis patch was $2.2 \mathrm{~m}$, which was significantly greater (Mann-Whitney $U$ test; $p<0.001)$ than the average distance from each female capture to the nearest $L$. pratensis patch, $0.0 \mathrm{~m}$. The distribution of females has a greater association with the distribution of $L$. pratensis (Fig. 2b): $38 \%$ of male capture locations overlapped with the distribution of $L$. pratensis, in comparison to $54 \%$ of female capture locations. The average distance between male captures to the nearest habitat edge was $8.9 \mathrm{~m}$, which was significantly smaller (Mann-Whitney U test; $\mathrm{p}<0.001)$ than the average distance between female captures and the nearest habitat edge, $12.6 \mathrm{~m}$, suggesting that males have a closer association with habitat edges than females. 

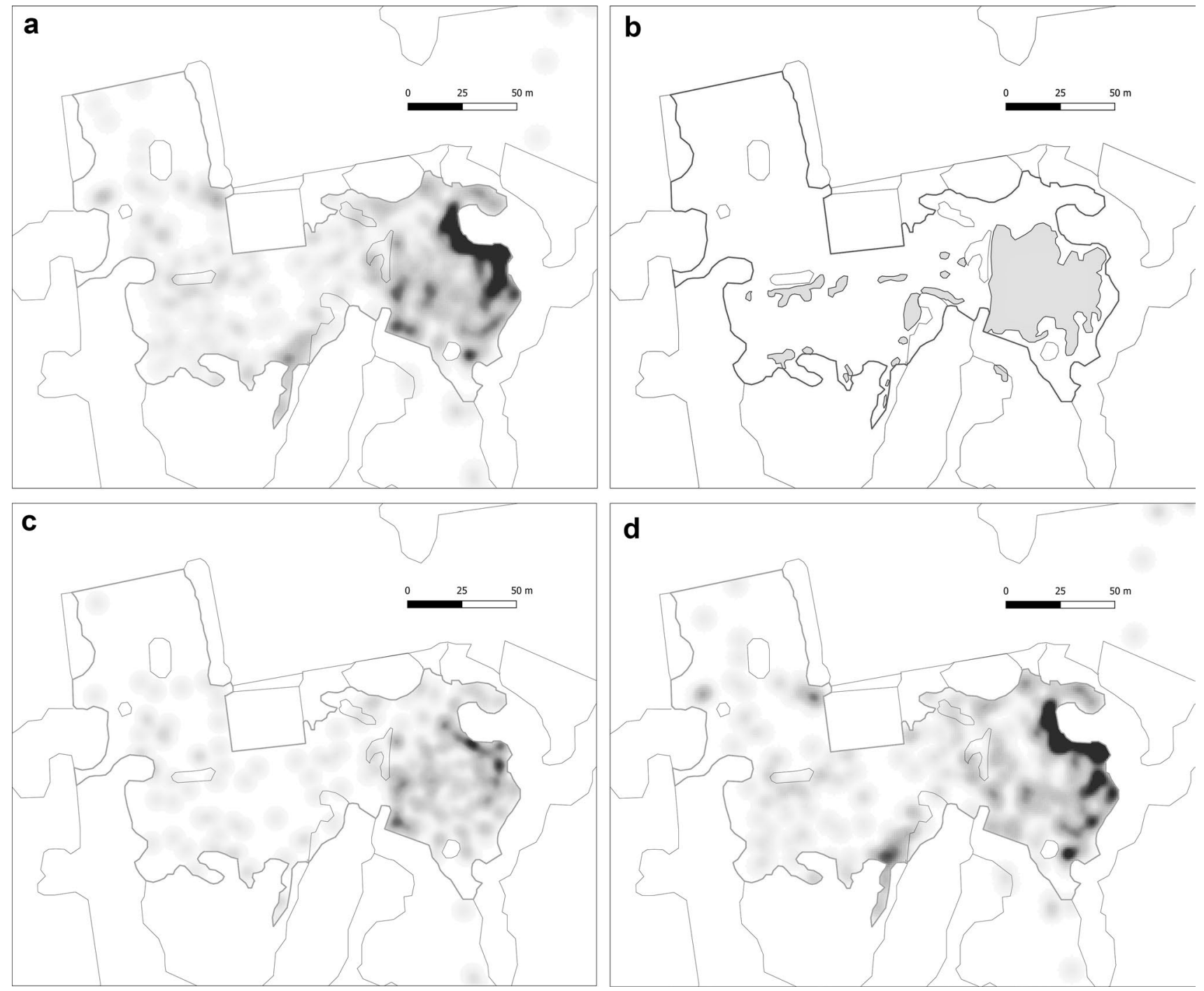

Fig. 2 Line maps of the study site. The main study area is represented as the area within the thick border. a Kernel density heat map illustrating the distribution and density for all captures of $L$. juvernica within the study area. Darker shaded areas represent greater densities of capture points, and, therefore, indicate favoured areas within the

site for L. juvernica; $\mathbf{b}$ the distribution of meadow vetchling L. pratensis within the study site, shown as the shaded areas. Kernel density heat maps illustrating the distributions and densities for all captures of $\mathbf{c}$ female, and $\mathbf{d}$ male $L$. juvernica within the study area

\section{Activity and behaviour}

Male $L$. juvernica tended to be more active than females. A significantly smaller proportion of males $(9.6 \%)$ were recorded at rest than females $(14.7 \%)\left(n=889, \chi^{2}=51.0\right.$, $d f=1, \mathrm{p}<0.001)$. Over short time periods, males were observed to fly greater distances than females. The average total direct distance which males were recorded to travel between recaptures on the same day $(92 \mathrm{~m})$ was significantly larger (Mann-Whitney $\mathrm{U}$ test; $\mathrm{p}<0.001)$ than the average recorded direct distance recorded for females $(51 \mathrm{~m})$. The maximum direct distance between same-day recaptures for males was $369 \mathrm{~m}$, over twice the maximum recorded for a

female, $177 \mathrm{~m}$. The mean direct distance between recaptures 1 day apart for males $(50 \mathrm{~m})$ was also significantly larger (Mann-Whitney U test; $\mathrm{p}<0.05$ ) than the corresponding average direct distance recorded for females $(38 \mathrm{~m})$. Direct distances measured between recaptures two or more days apart were not significantly different between males and females.

Copulation was observed only twice; the first observation involved two apparently freshly emerged individuals which had not been previously marked. The second observation involved a fresh, unmarked female, and a marked male, which had first been caught 10 days previously, and was in poor bodily condition. Twenty-seven instances of 


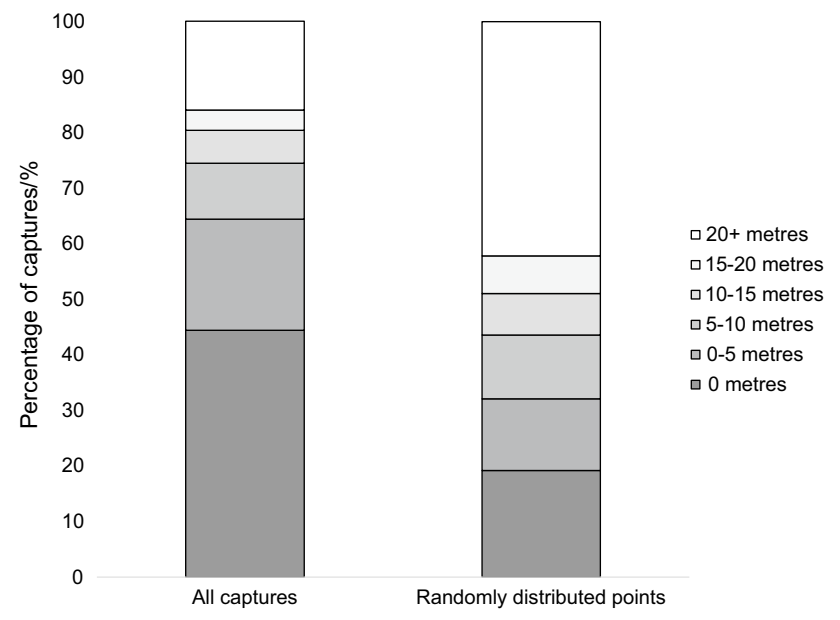

Fig. 3 The proportions of $L$. juvernica captures (left, $\mathrm{n}=844$ ) recorded at varying distances from the nearest patch of $L$. pratensis, compared to the proportion of distances extracted from the same number of points randomly distributed across the study area (right, $\mathrm{n}=844$ )

oviposition were recorded: on all occasions, a single egg was laid on L. pratensis. A female was observed inspecting and curving her abdomen in an ovipositing manner on gorse Ulex europaeus, but was disturbed before more observations could be made. The same female had been previously observed ovipositing on L. pratensis. Observed locations for oviposition were strongly biased towards the east side of the study area (Fig. 4), coinciding with the areas with the greatest abundance of adult females (Fig. 2c) and most L. pratensis. Oviposition sites tended to be in the open, relatively short sward, away from habitat edges. The mean distance from oviposition sites to habitat edges was $22.4 \mathrm{~m}$ (min. $8.0 \mathrm{~m}$; max. $41.8 \mathrm{~m}$ ).

There were 71 observations of $L$. juvernica feeding on nectar at flowers. Most of these records were for females, representing a significant female bias overall $(n=71$, $\left.\chi^{2}=30.8, d f=1, \mathrm{p}<0.001\right)$. Seven species were used for foraging, the most frequent being bush vetch Vicia sepium, followed by ragged robin Lychnis flos-cuculi and common vetch Vicia sativa (Table 2). Foraging was recorded widely across the study area, as Vicia sepium and V. sativa were widespread across the open habitats frequented by $L$. juvernica.

Leptidea juvernica was recorded at rest on 102 occasions. Many of these events occurred during spells of poor weather, or late in the day when L. juvernica tends to stop flying, and rests high on vegetation, basking in evening sun. The distribution of locations where individuals were recorded at rest, as well as the distribution of tall, rank sward are shown in Fig. 5. There was a strong association between resting individuals and the areas of tall, rank sward or long herbaceous vegetation, usually at the base of scrub and trees $(n=228$, $\left.\chi^{2}=245.53, d f=1, \mathrm{p}<0.001\right)$. This was apparent on fine
Fig. 4 Map of the study area showing the distribution of the larval host-plant, $L$. pratensis, shown in as the shaded areas; and the locations where oviposition was recorded to have taken place, shown as points $(n=27)$

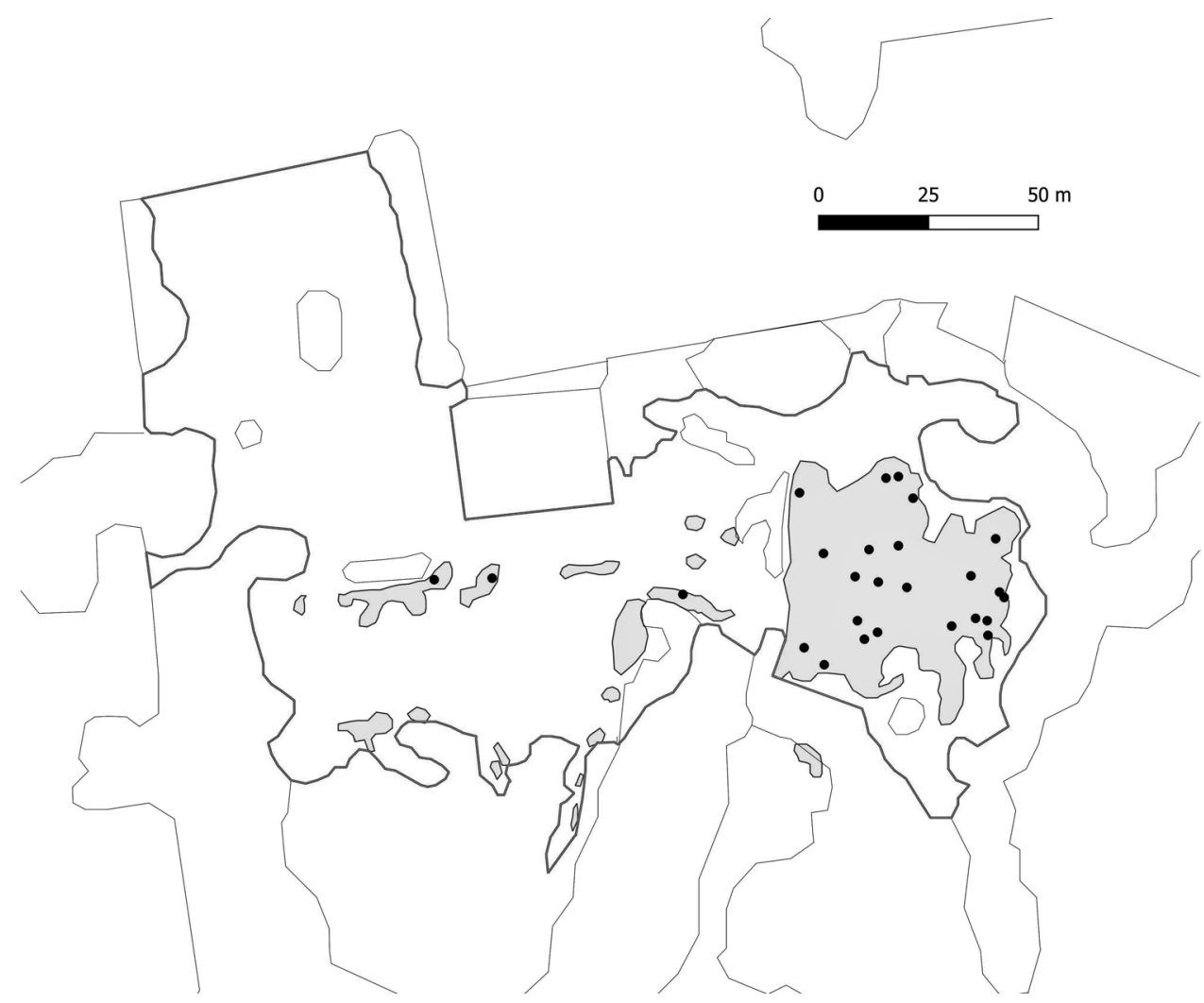


Table 2 Plant species on which L. juvernica was observed to have used during foraging, and respective number and percentage of observations for each species

\begin{tabular}{lcc}
\hline Nectar plant species & $\begin{array}{l}\text { Number of } \\
\text { observations }\end{array}$ & \% of total \\
\hline Bush vetch (Vicia sepum) & 50 & 70.4 \\
Ragged robin (Lychnis flos-cuculi) & 9 & 12.6 \\
Common vetch (Vicia sativa) & 6 & 8.4 \\
Meadow buttercup (Ranunculus acris) & 2 & 2.8 \\
Red clover (Trifolium pratense) & 2 & 2.8 \\
Meadow vetchling (L. pratensis) & 1 & 1.4 \\
Hoary willowherb (Epilobium parviflorum) & 1 & 1.4 \\
\hline
\end{tabular}

evenings; small aggregations of 2-15 L. juvernica gathered to roost in sheltered areas of long grass and stinging nettles Urtica dioica.

\section{Off-site dispersal}

Searches of the River Bann floodplain adjacent to the study site as far as $1 \mathrm{~km}$ to the south, as well as opportunistic captures elsewhere, resulted in 31 captures. These had a southern bias, with the furthest capture recorded $269 \mathrm{~m}$ from the study area. Most off-site captures were located along linear features, such as hedgerows and habitat edges. All but one of the off-site captures were male. Twenty-three were recaptures of individuals previously marked on the study area, and eight were individuals captured for the first time and marked off-site. Of these, six were recaptured subsequently on the study area, and two were not recaptured.

Fourteen individuals were observed to make return journeys back to the study area. One, Male \#23, made three separate return journeys off-site (one to the south, two to the north), between being marked (during copulation with Female \#22) on the study area on the 16th May and its death on the study area on or after the 27th May. The total minimum distance between all captures for Male \#23 was $1311 \mathrm{~m}$.

\section{Discussion}

\section{Population demographics}

Protandry, in Lepidoptera, is defined as the emergence of adult males before females, mutually optimising the reproductive success of both sexes (Wiklund and Fagerström 1977; Fagerström and Wiklund 1982). It is common in species of butterflies where the seasonal flight season is restricted to within a short time window, as in European Pieridae, such as Pieris napi (Forsberg and Wiklund 1988), and Anthocharis cardamines (Thomas 2010). It is known from $L$. sinapis in England, where males can emerge around
Fig. 5 Map of the study area showing the main distribution of areas of tall, rank sward, shown as the shaded areas; and the locations of captures of L. juvernica recorded at rest, shown as points

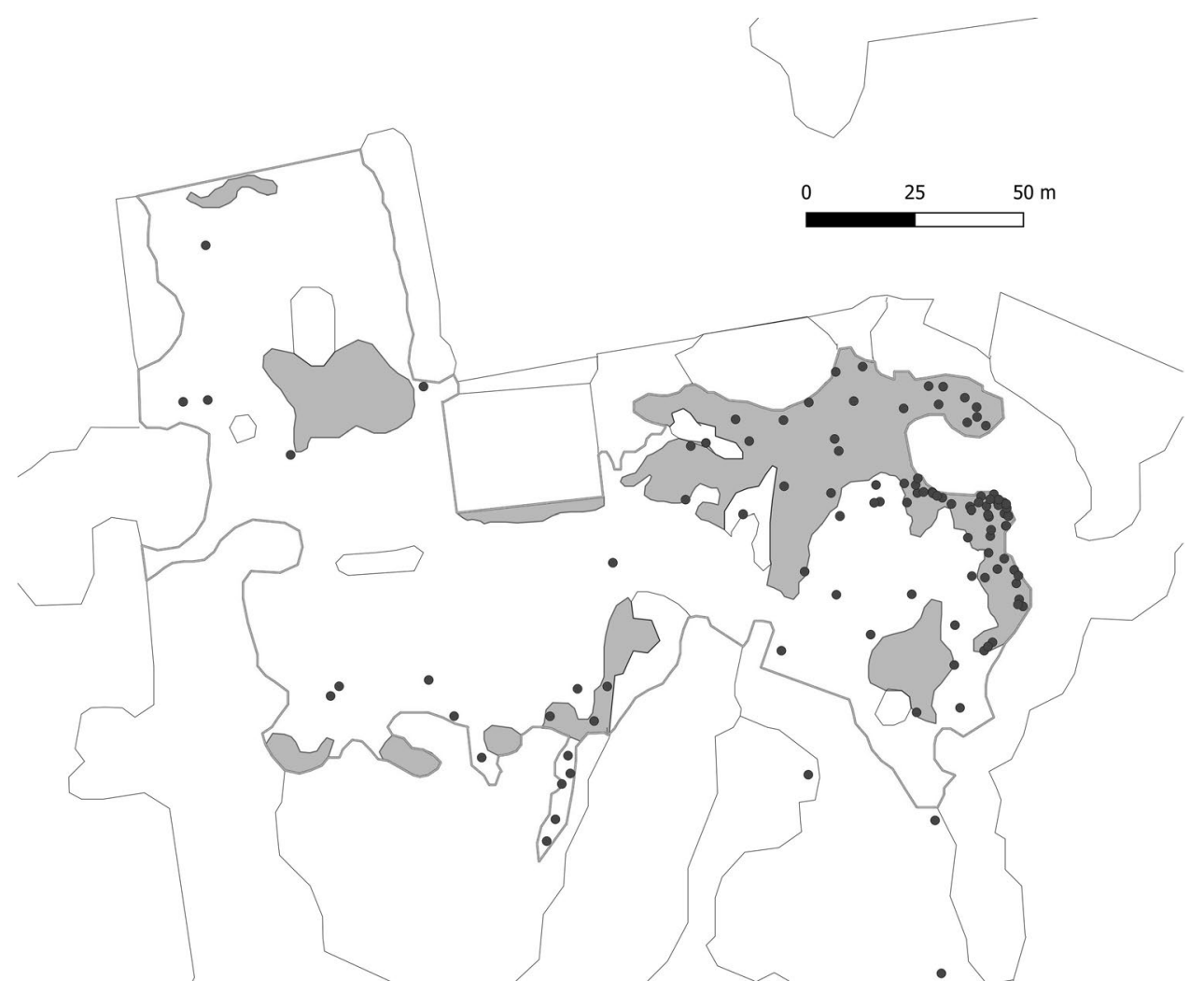


1 week before females (Warren et al. 1986) and occurs in both $L$. juvernica and L. sinapis in Sweden (Wiklund and Solbreck 1982; Friberg et al. 2008). It is interesting, therefore, that during the period of study in 2016, there was little evidence of protandry in the Edenderry population of $L$. juvernica, where both sexes have a strong emergence at the beginning of the flight season, and peak in number on the same date, although females remain at peak numbers after males have begun to decrease after the 30th May (Fig. 1). Friberg et al. (2008) showed that both Leptidea species in Sweden show obligatory protandry under standard conditions, with males tending to emerge considerably earlier (1-3 days) than females from pupae kept in controlled environmental conditions. This suggests that a sudden change in daily temperatures in the weeks prior to the emergence of $L$. juvernica at Edenderry in 2016 may have disrupted normal development of the chrysalises. The first week of May was cool with maximum daily temperatures of $11-15{ }^{\circ} \mathrm{C}$. From 7th to 13th May, the maximum daily temperature rose to $21-23^{\circ} \mathrm{C}$, and the first flying $L$. juvernica were observed on 11th May. Cool temperatures, followed by a sudden increase in temperature, may reduce the developmental differences between male and female chrysalises, resulting in closer synchrony of emergence times in the early part of the flight season. Further demographic studies from a range of locations, and experimentation with captive chrysalises in controlled environments, is required to investigate the potential effect of climate and weather conditions on protandry in Irish $L$. juvernica.

Weather conditions also appeared to have some effect on the daily population estimates of $L$. juvernica across the flight season. Figure 1 shows fluctuations in the daily population estimates prior to the flight season peak on the 30th May. As survival/residence rates were estimated to be constant for males and females during the flight period and there is no evidence of significant immigration into this isolated population, variable environmental conditions will have affected the population estimates in two ways: with lower temperatures and unfavourable conditions, recruitment of new individuals into the population will be lower; and the probability of encountering individuals is lower, as the butterflies are less active. The best-fit model used to estimate the population sizes did not take into account variation in encounter probability over the survey period, and so most population estimation fluctuations are likely exaggerated by this limitation. However, a probable direct effect of the weather conditions was most noticeable between the 24th and 27th May when the daily maximum temperature reached a low of $13{ }^{\circ} \mathrm{C}$. Despite a rise in temperature and increase in sunshine hours on the 27th May, the total estimated population had dropped to 38 from a minor peak of 56 on the 24th May. The estimated population increased on the 28th May, suggesting that there is a lag of approximately 1 day between changes in temperature and the responding change in daily numbers of butterflies. This lag effect was supported by comparing observed numbers of $L$. juvernica in the field during surveys events against daily maximum temperatures; in particular, it was noted at the time that there were noticeably few butterflies encountered (23) on the 27th May despite favourable weather conditions. In comparison, there were 48 encountered on the 28th May, when the daily maximum temperature recorded was merely $1^{\circ}$ higher. Depending on the predominant mortality pressures that $L$. juvernica faces at Edenderry, survival is unlikely to be affected by brief spells of mildly adverse weather conditions, as butterflies lie low in vegetation, in a state of torpor, and resume activity with an increase in temperature. Emergence is more likely to be affected by temperature, as insect development and growth are linked closely to environmental conditions, particularly temperature (Ratte 1984).

The recorded residence times for individual $L$. juvernica are likely to be underestimates, as the individuals may have emerged for a time before marking, and survived for a time after their last capture. The maximum recorded period of survival/residence (19 and 18 days for males and females, respectively) is shorter than that recorded by Clarke et al. (2011) for L. sinapis in England (26 and 27 days for males and females, respectively). Similarly, Friberg et al. (2008) found that, in Sweden, the maximum lifespan in adult $L$. sinapis (26 days for males and females) was greater than in L. juvernica (23 and 21 days for males and females respectively). Mortality in L. juvernica may in part be a result of injury, possibly caused by general activity among dense vegetation over time, in addition to predation and energy deficit pressures. Differences in survival times between species may be due to habitat differences where $L$. sinapis is largely restricted to sheltered woodland rides and edges, and L. juvernica, found mainly in open habitats, is more exposed to adverse weather conditions such as wind and rain, which may increase chance of injury to the wings earlier in adult life. The significantly higher proportion of injured males than females observed in the present study likely arose due to higher levels of activity and, thus, chance of harm in males.

The higher incidence of male than female captures (Table 1) is most likely the direct result of a higher level of activity in the former; (Wiklund 1977) and thus the higher chance of encountering males. It is probable that the sex ratio of adult $L$. juvernica is close to $1: 1$. This has been shown to be the case in British L. sinapis, which demonstrated a 1:1 sex ratio through the sexing of pupae found by searching suitable habitat, despite subsequent surveys of adults being dominated by males (Warren 1981).

The estimate for the total population of 257 L. juvernica at Edenderry over the survey period clearly suggests that $L$. juvernica populations can reach high numbers, even on 
small sites, and can, temporarily, become the most abundant butterfly species present. More extensive tracts of habitat, may support populations numbering into the thousands. Large population sizes can protect populations against inbreeding, and detrimental genetic and environmental stochasticity, which can drive extinctions of small, localised populations (Habel and Schmitt 2012). However, even large populations of butterflies can fluctuate considerably in response to climatic factors or parasitism (Ehrlich 1992), and further investigations on long-term population trends and influences should be carried out on L. juvernica as they have on L. sinapis (Warren et al. 1986).

\section{Spatial ecology}

The association between the distribution and abundance of adult $L$. juvernica and the distribution of its larval host-plant is common to habitat-specialist temperate butterflies found in open habitats (Munguira et al. 1997; Casacci et al. 2011). Maintaining close proximity to major breeding areas benefits males in that they are more likely to find newly-emerged virgin females with which to mate, and benefits females as they are able to lay large numbers of eggs quickly. As with most European butterfly species (Scott 1973), female L. juvernica are usually mated within a day after emergence, and are less active than males, spending a smaller proportion of their life in flight (Wiklund 1977), and flying shorter distances, features L. juvernica shares with L. sinapis (Warren et al. 1986). In contrast, male L. juvernica have a high level of activity, patrolling over wider areas in search of receptive females, and moving between patches of breeding habitat. Thus, females had a greater affiliation with patches of $L$. pratensis than males. Such disparate spatial preferences between the sexes suggest that the optimum environment for L. juvernica consists of a patchwork of habitats; open grassland for reproduction and larval development, with areas of tall scrub, trees and wooded edges to provide shelter for the purposes of courtship and roosting.

Wiklund (1977) found that female Leptidea spp. in Sweden utilise separate foraging and breeding habitats, preferring to lay eggs on host-plants in open meadow habitat, and foraging exclusively within woodland glades. This did not appear to be the case at Edenderry, where oviposition and foraging often took place in the same areas. Some females alternated quickly between feeding and oviposition, apparently depending on which plant species they encountered during their low, slow 'questing' flights.

L. juvernica particularly favoured the wooded edge on the north-east side of the study area (Fig. 2a), but it was mainly males which dominated this area (Fig. 2d). This was likely to be due to a combination of its close proximity to a large patch of larval host-plants, and was south facing and sheltered, and, hence, attractive to the relatively weak-flying, warmth-loving $L$. juvernica. This area, like other habitat edge areas within the site, was dominated by tall, rank vegetation (Fig. 5), which contained little L. pratensis. Hence, female $L$. juvernica were forced to spend more time further out in the open in order to lay eggs. Males remained in the warmer, sheltered habitat edges, whilst maintaining close proximity to the main area containing females. More females than males were recorded at rest, which took place in tall swards along habitat edges. Thus, females that were not foraging or ovipositing spent time at rest along the sheltered habitat edges. With males wandering over greater distances, aggregations of males were recorded in isolated, often southfacing, sheltered spots across the study area some distance away from the main breeding area in the east, as well as along the wooded edge to the south of the study area.

Oviposition generally occurred on low-growing hostplants in relatively short sward in open habitats, consistent with Warnock (2008) who found that L. juvernica in Ireland lay their eggs on host-plants around $17-23 \mathrm{~cm}$ above the ground. In comparison, L. sinapis in England will lay on host-plants at heights ranging from near ground-level in areas of largely bare ground (Jeffcoate 2006), to between $30-50 \mathrm{~cm}$ on taller protruding host-plants, surrounded by tall vegetation (Warren 1984; Clarke et al. 2011). Females of both species may choose oviposition sites based on perceived optimum temperature for the development of early stages at the time of laying (Clarke et al. 2011). Thus, differences in oviposition locations between species may reflect higher temperatures closer to the ground in the open habitats used by $L$. juvernica, whereas in the sheltered habitats of $L$. sinapis, optimum temperatures at the time of oviposition may be found further above the ground level, although this will vary depending on exact location.

Off-site movements of L. juvernica were likely to be under-recorded, as a larger search area with unsuitable habitat types, and limited effort available, resulted in a lower probability of encountering $L$. juvernica across the River Bann floodplain to the south. Most of the suburban areas to the east, north and west of Edenderry were inaccessible or complicated to navigate, reducing the chance of encountering any L. juvernica moving through these areas. However, the data that were collected are sufficient to show that some individuals were able to return to the study area after moving off-site, up to three times. It is not known if this was down to chance, with butterflies flying in random directions, following linear features, or evidence of navigational ability. Many individuals recorded off-site would have crossed barriers, e.g. areas of tall scrub or $>10 \mathrm{~m}$ tall trees. Despite normally flying low in open grassland, L. juvernica were observed on three occasions to leave the study area by high-level flight over tall hedgerows, scrub, or buildings. As the Edenderry population likely dates from 2013, one or more founding individuals most likely originated from one of the nearest 
breeding populations which are separated from Edenderry by expanses of urban environments, open pasture, woodland, and open water greater than surveyed in the present study. This suggests that, in a metapopulation context, L. juvernica is capable of crossing physical considerable barriers, moving between areas of suitable breeding habitat, leading to genetic flow between populations, and colonisation of new areas.

\section{Conclusion}

This study of the cryptic wood white $L$. juvernica confirm important similarities and differences between $L$. juvernica and L. sinapis in Britain and Ireland. Both species have short generational flight periods (bivoltine in L. sinapis, univoltine in L. juvernica), and while protandry is known from L. sinapis, it was not strongly observed in this study of $L$. juvernica; further investigation is required to establish the cause of this, and whether this is anomalous or normal for $L$. juvernica in Ireland. They depend on the same set of larval host-plant species, but have a clear difference in habitat preference, with $L$. juvernica usually found in open grassland and sparse scrubby areas, whilst $L$. sinapis is mainly found in rides and glades in mature woodland.

With a total of 256 individual adult $L$. juvernica estimated to have been present on this small, suburban site in the space of 38 days, and a very high recapture rate, the mark-release-recapture element of this study showed that populations of L. juvernica can reach high densities during the peak flight season which is beneficial for protecting populations against inbreeding, stochastic events and parasitism and predation pressures, and increases the likelihood of emigration from the population, leading to increased connectivity and colonisation within a metapopulation. Recruitment of newly emerging adults into the population may be set back by unfavourable weather conditions. Males were more often encountered than females, most likely due to observed greater activity levels in males, rather than a skewed sex ratio.

Male and female L. juvernica showed different preferences in their spatial organisation within their environment, with males more closely associated with sheltered woody habitat edges, and females associated with open grassy habitats. This is presumed to reflect the different requirements of the sexes, with ovipositing females remaining close to suitable stands of larval host-plant, and males waiting for virgin females in the warm, sheltered habitat edges. Such spatial ecological preferences of $L$. juvernica should be taken into account in conservation management of this priority species. Whilst $L$. juvernica is commonly associated with open grassland, the importance of tall woody vegetation, scrub and trees for this species should not be underestimated, and ideally a close patchwork of habitats should be created. Despite appearing to have relatively weak flight, L. juvernica has shown that it can cross reasonably large distances over unsuitable habitats. It is desirable to establish and maintain connections between neighbouring populations in order to maintain gene flow and reduce the risk of local extinctions through stochastic events. Landscape management measures may consist of the creation of small patches of suitable habitat between breeding areas, so that dispersing individuals may 'island-hop' from one population to another. As $L$. juvernica tends to follow linear features, hedgerows and woodland edge between populations may be managed to lead dispersing butterflies between breeding habitat patches, whilst removal of hedgerows and scrub is likely to have a negative impact on connectivity between populations of $L$. juvernica.

Acknowledgements The authors thank Hannah Lehnhart-Barnett for assistance with fieldwork, and Dr. Tom Brereton and Catherine Bertrand of Butterfly Conservation, Dr. Brian Nelson of the Irish National Parks and Wildlife Service, and Professor Christer Wiklund of the Stockholm University Department of Zoology, for their help, advice and support.

\section{Compliance with Ethical Standards}

Conflict of interest Author James O'Neill is a member of the committee for the Northern Ireland Branch of the UK charity Butterfly Conservation.

Informed consent This article does not contain any studies with human participants performed by any of the authors.

Research involving animal participants All applicable international, national, and/or institutional guidelines for the care and use of animals were followed. This research heavily involved contact with wild animals (butterflies), and every effort was made to uphold welfare standards to reduce the likelihood of bodily harm or decreased survival as a result of the capture-marking-recapture process. This included gentle capture, handling and release methods in suitable locations and conditions, and a method of marking the butterflies' wings which was considered to have little effect on survival.

Open Access This article is distributed under the terms of the Creative Commons Attribution 4.0 International License (http://creativeco mmons.org/licenses/by/4.0/), which permits unrestricted use, distribution, and reproduction in any medium, provided you give appropriate credit to the original author(s) and the source, provide a link to the Creative Commons license, and indicate if changes were made.

\section{References}

Allen D, Mellon C (2006) Leptidea reali real's wood white: Northern Ireland's Priority Species. National Museums Northern Ireland. http://www.habitas.org.uk/priority/species.asp?item=430857. Accessed 6 Dec 2017

Beneš J, Konvicka M, Vrabec V, Zamecnik J (2003) Do the sibling species of small whites, Leptidea sinapis and L. reali (Lepidoptera, 
Pieridae) differ in habitat preferences? Biologia-Bratislava 58:943-952

Bickford D, Lohman D, Sodhi N, Ng P, Meier R, Winker K, Ingram K, Das I (2007) Cryptic species as a window on diversity and conservation. Trends Ecol Evol 22:148-155

Casacci L, Witek M, Barbero F, Patricelli D, Solazzo G, Balletto E, Bonelli S (2011) Habitat preferences of Maculinea arion and its Myrmica host ants: implications for habitat management in Italian Alps. J Insect Conserv 15:103-110

Clarke S, Green D, Joy J, Wollen K, Butler I (2011) Leptidea sinapis (wood white butterfly) egg-laying habitat and adult dispersal studies in Herefordshire. J Insect Conserv 15:23-35

Dincă V, Lukhtanov V, Talavera G, Vila R (2011) Unexpected layers of cryptic diversity in wood white Leptidea butterflies. Nat Commun 2:324

Ehrlich P (1992) Population biology of checkerspot butterflies and the preservation of global biodiversity. Oikos 63:6-12

Fagerström T, Wiklund C (1982) Why do males emerge before females? Protandry as a mating strategy in male and female butterflies. Oecologia 52:164-166

Forsberg J, Wiklund C (1988) Protandry in the green-veined white butterfly, Pieris napi L. (Lepidoptera; Pieridae). Funct Ecol 2:81-88

Friberg M, Wiklund C (2009) Host plant preference and performance of the sibling species of butterflies Leptidea sinapis and Leptidea reali: a test of the trade-off hypothesis for food specialisation. Oecologia 159:127-137

Friberg M, Bergman M, Kullberg J, Wahlberg N, Wiklund C (2008) Niche separation in space and time between two sympatric sister species - a case of ecological pleiotropy. Evol Ecol 22:1-18

Habel J, Schmitt T (2012) The burden of genetic diversity. Biol Conserv 147:270-274

Heal H (1965) The wood white, Leptidea sinapis L., and the railways. Ir Nat J 15:8-13

Jeffcoate $S$ (2006) Seasonal variation in the use of vegetation resources by Leptidea sinapis (Linnaeus, 1758) (Lepidoptera: Pieridae), a multivoltine species in southern Britain: implications for its conservation at the edge of its range and in the context of climate change. Entomol Gaz 57:69

Jeffcoate S, Joy J (2011) Evidence-based national recovery plan for Leptidea sinapis (wood white butterfly) in southern Britain. J Insect Conserv 15:759-763

Jennersten O (1984) Flower visitation and pollination efficiency of some North European butterflies. Oecologia 63:80-89

Konvička M, Kuras T (1999) Population structure, behaviour and selection of oviposition sites of an endangered butterfly, Parnassius mnemosyne, in Litovelské Pomoravíl. Czech Republic. J Insect Conserv 3:211-223

Munguira M, Martín J, García-Barros E, Viejo L (1997) Use of space and resources in a Mediterranean population of the butterfly Euphydryas aurinia. Acta Oecol 18:597-612
Nash D, Boyd T, Hardiman D (2012) Ireland's butterflies: a review. The Dublin Naturalist's Field Club, Dublin

Nelson B, Hughes M, Nash R, Warren M (2001) Leptidea reali Reissinger 1989 (Lep.: Pieridae): a butterfly new to Britain and Ireland. Entomol Rec J Var 113:97-101

Ratte H (1984) Temperature and insect development. In: Environmental physiology and biochemistry of insects. Springer, Berlin, pp 33-66

Reissinger E (1989) Checklist Pieridae DUPONCHEL, 1835 (Lepidoptera) der Westpaläarktis (Europa, Nordwestafrika, Kaukasus, Kleinasien). Atalanta 20: 149-185

Sachanowicz K, Wower A, Buszko J (2011) Past and present distribution of the cryptic species Leptidea sinapis and L. reali (Lepidoptera: Pieridae) in Poland and its implications for the conservation of these butterflies. Eur J Entomol 108:235

Scott J (1973) Mating of butterflies. J Res Lepid 11:99-127

Staats W, Regan E (2014) Initial population trends from a 5-year butterfly monitoring scheme. J Insect Conserv 18:365-371

Thomas J (1995) The conservation of declining butterfly populations in Britain and Europe: priorities, problems and successes. Biol J Lin Soc 56:55-72

Thomas J (2010) Butterflies of Britain and Ireland, 3rd edn. British Wildlife Publishing, Oxford

Thompson R, Nelson B (2006) The butterflies and moths of northern Ireland. Blackstaff Press, National Museums Northern Ireland, Belfast

Warnock N (2008) The ecology and conservation of Leptidea reali (Real's Wood White) in Northern Ireland. MSc thesis, Queen's University Belfast

Warren MS (1981) Population ecology of the wood white butterfly Leptidea sinapis $\mathrm{L}$. PhD thesis, University of Cambridge

Warren M (1984) The biology and status of the wood white butterfly Leptidea sinapis (L.) (Lepidoptera: Pieridae), in the British Isles. Entomol Gaz 35:207-223

Warren M, Pollard E, Bibby T (1986) Annual and long-term changes in a population of the wood white butterfly Leptidea sinapis. $\mathrm{J}$ Anim Ecol 55:707-719

Watt W, Chew F, Snyder L, Watt A, Rothschild DE (1977) Population structure of pierid butterflies. Oecologia 27:1-22

Wiklund C (1977) Oviposition, feeding and spatial separation of breeding and foraging habitats in a population of Leptidea sinapis (Lepidoptera). Oikos 28:56-68

Wiklund C, Fagerström T (1977) Why do males emerge before females? Oecologia 31:153-158

Wiklund C, Solbreck C (1982) Adaptive versus incidental explanations for the occurrence of protandry in butterfly, Leptidea sinapis L. Evolution 36:56-62

Williams H (1946) The Irish form of Leptidea sinapis L. Entomologist 79:1-3 